\title{
METODOLOGIA DO ENSINO SUPERIOR COM TECNOLOGIAS DA INFORMAÇÃO E COMUNICAÇÃO: ESTRATÉGIAS DE ENSINO EXPERIENCIADAS
}

\begin{tabular}{c}
\hline METHODOLOGY OF HIGHER EDUCATION WITH \\
INFORMATION AND COMUNICATION TECHNOLOGIAS: \\
EXPERIENCED TEACHING STRATEGIES \\
\hline METODOLOGÍA DE LA ENSEÑANZA SUPERIOR CON \\
TECNOLOGÍAS DE LA INFORMACIÓN Y COMUNICACIÓN: \\
ESTRATEGIAS DE ENSEÑANZA EXPERIENCIAS \\
\hline
\end{tabular}

RESUMO: Este relato de experiência apresenta a investigação de metodologias educacionais com o uso das tecnologias da informação e comunicação (TIC) como ferramentas norteadoras no processo de promoção e inovação da qualidade do ensino superior. Descreve uma experiência envolvendo exploração de estratégias didáticas com recursos das TIC em aulas da disciplina "Metodologia do Ensino Superior com TIC", ofertada aos mestrandos, doutorandos e discentes especiais do Programa de Pós-Graduação em Educação (PPGE) da Universidade Federal de Alagoas (UFAL), no segundo semestre do ano letivo de 2016. Apresenta o relato das atividades curriculares com utilização de TIC trabalhadas na disciplina, envolvendo a seleção de recursos tecnológicos, subsidiando aulas dinâmicas e colaborativas, em que o conhecimento a ser construído se deu de forma compartilhada num espaço interativo entre docente e estudantes. O referencial teórico é fundamentado em Masetto (1998), Debald (2003), Zabalza (2004), Mauri e Onrubia (2010) e Mercado (2015). Como resultados são descritas as estratégias metodológicas utilizadas durante o percurso da disciplina, mostrando possibilidades de práticas metodológicas para a promoção da qualidade e da inovação no que diz respeito à docência no ensino superior.

PAlAVRAS-ChAVE: TIC. Prática pedagógica. Estratégias didáticas. Formação de docentes do ensino superior.

ABSTRACT: This experience report presents the investigation of educational methodologies with the use of information and communication technologies (ICT) as guiding tools in the process of promotion and innovation on the quality of higher education. Describes an experience involving the exploration of didactic estrategies with ICT resources in classes of the discipline "Methodology of Higher Education with ICT", offered to the masters, doctoral students and special students of the Postgraduate Program in Education (PPGE) of the Federal University of Alagoas (UFAL), in the second semester of the 2016 academic year. It presents the report of curricular activities with use of ICT worked in the discipline, involving the selection of technological resources, subsidizing dynamic and collaborative classes, in which the knowledge to be constructed was given form shared in an interactive space between teachers and students. The theoretical framework is based on Masetto (1998), Debald (2003), Zabalza (2004), Mauri and Onrubia (2010) and Mercado (2015). The results describe the methodological strategies used during the course of the course, showing possibilities of methodological practices for the promotion of quality and innovation in teaching in higher education.

KEYWORDS: TIC. Pedagogical practice. Didactic strategies. Teacher training in higher education.

\footnotetext{
${ }^{1}$ Submetido em: 28/04/2018 - Aceito em: 20/06/2018 - Publicado em: 11/01/2019
}

\begin{tabular}{l|l|l|l|l|l|l} 
(C) Rev. Educ. Perspec. & Viçosa, $M G$ & v.9 & n.2 & p.453-478 & maio/ago. 2018 & eISSN 2178-8359 \\
\hline
\end{tabular}


RESUMEN: Este relato de experiencia presenta la investigación de metodologías educativas con el uso de las tecnologías de la información y comunicación (TIC) como herramientas orientadoras en el proceso de promoción e innovación de la calidad de la enseñanza superior. En el presente trabajo se analizan los resultados obtenidos en el análisis de los resultados obtenidos en el análisis de los resultados obtenidos en el estudio. En el segundo semestre del año escolar de 2016. Presenta el relato de las actividades curriculares con utilización de TIC trabajadas en la disciplina, involucrando la selección de recursos tecnológicos, subsidiando clases dinámicas y colaborativas, en que el conocimiento a ser construido se dio de forma compartida en un espacio interactivo entre docentes y estudiantes. El referencial teórico es fundamentado en Masetto (1998), Debald (2003), Zabalza (2004), Mauri y Onrubia (2010) y Mercado (2015). Como resultados se describen las estrategias metodológicas utilizadas durante el recorrido de la disciplina, mostrando posibilidades de prácticas metodológicas para la promoción de la calidad y la innovación en lo que se refiere a la docencia en la enseñanza superior.

PAlabras Clave: TIC. Práctica pedagógica. Estrategias didácticas. Formación de docentes de la enseñanza superior.

\section{INTRODUÇÃO}

$\mathrm{Na}$ atualidade, o ensino superior e as práticas docentes enfrentam algumas mudanças e desafios advindos do uso das tecnologias da informação e comunicação (TIC) na sociedade. Novas competências docentes são exigidas e surgem novos desafios no ensino superior, consonante a integração das TIC no processo de ensino-aprendizagem. Um deles é o desenvolvimento de estratégias pedagógicas inovadoras, que objetivem o diálogo, construção colaborativa, formação autônoma, reflexiva e uma educação de qualidade, voltada para atender os alunos.

Para Masetto (1998), o docente do ensino superior, deve estar atento às mudanças sociais, em formação constante, para conhecer o potencial pedagógico que as TIC oferecem quando usadas adequadamente. Serra e Silva (2008) esclarecem que o meio educacional, tendo em vista o potencial de viabilização do conhecimento que as TIC proporcionam, de forma rápida e interativa, cria possibilidades de ensino para além do ambiente da sala de aula presencial. Já para Silva (2017), é preciso que os docentes desenvolvam as competências necessárias para a integração das TIC em sua prática docente, migrando das metodologias centradas no docente para metodologias e atividades online centradas no estudante.

A integração das TIC ao currículo é fundamental quando se pensa em tornar a aula significativa e dinâmica, assim como o desenvolvimento de estratégias didáticas que torne o curso mais dinâmico, desafiador, criativo e renovado. De acordo com Pozo, Monereo e Castelló (1996), estratégias adequadas permitirão um melhor processo de aprendizagem.

Visando contribuir para a prática docente e estudos na área, este relato apresenta estratégias de ensino com uso das TIC, experenciadas na disciplina de "Metodologia do Ensino Superior com TIC” do Programa de Pós-Graduação em Educação (PPGE) da Universidade Federal de

\begin{tabular}{l|c|c|c|c|c|c} 
(C) Rev. Educ. Perspec. & Viçosa, $M G$ & v.9 & n.2 & p.453-478 & maio/ago. 2018 & eISSN 2178-8359 \\
\hline
\end{tabular}


Alagoas (UFAL), ofertada em 2016, com atividades que utilizaram diversos recursos digitais, envolvendo metodologias voltadas para o ensino superior.

Inicialmente caracterizamos o docente do ensino superior e suas competências frente ao uso das TIC no ensino superior, suscitando a importância de metodologias que conduzam a um ensino contextualizado e de qualidade, levando a reflexão das atribuições do docente no ensino que "em lugar de meros instrutores ou apresentadores, sejam de fato educadores em nosso tempo" (SILVA; SANTOS, 2006, p. 35).

\section{DOCÊNCIA DO ENSINO SUPERIOR}

O docente do ensino superior atualmente se caracteriza por seu aspecto de formação profissional em poder atuar em várias funções da prática pedagógica, da pesquisa às atividades administrativas. Neste contexto, emergem também no cenário atual da educação brasileira novos valores balizados pela lógica da produtividade e do mercado. Isto remete à incessante busca dos docentes por publicações, qualificação, diplomação, cursos de aperfeiçoamento e demais indicadores de classificação e avaliação institucional.

As instituições de ensino superior (IES) de acordo com Masetto (1998, p. 23) são espaços de encontro e convivência entre educadores e educandos, que se reúnem e trabalham para que ocorram situações favoráveis ao "desenvolvimento dos aprendizes nas diferentes áreas do conhecimento, no aspecto afetivo-emocional, nas habilidades e nas atitudes e valores”. À luz do desenvolvimento humano para a melhoria da vida da população, o autor citado destaca como importante para formação do docente do ensino superior, a formação simultânea, a formação acadêmica, a flexibilização e dinamização curricular, a revitalização da vida acadêmica pela atividade profissional, a desestabilização de currículos fechados e acabados, apresentando-se como características essenciais para o saber deste profissional.

Masetto (1998) afirma que para o docente universitário adquirir a conotação de profissionalismo e realizar atividades de sua competência como a pesquisa, o processo de ensino-aprendizagem e a gestão pedagógica e administrativa, se exige deste profissional também o desenvolvimento de competências próprias: domínio em determinada área do conhecimento; docente como receptor e gestor de currículo; domínio na relação docenteestudante e estudante-estudante; conhecimento básico da tecnologia educacional: teoria e prática; orientação pedagógica para estudante; gestão pedagógica e administrativa; domínio no processo ensino-aprendizagem; domínio na área pedagógica; domínio específico de uma área de pesquisa; conhecimentos e práticas profissionais atualizadas. $\mathrm{O}$ docente do ensino superior envolvido em inúmeras atuações e funções dentro e fora da IES.

\begin{tabular}{l|c|c|c|c|c|c} 
(C) Rev. Educ. Perspec. & Viçosa, $M G$ & v.9 & n.2 & p.453-478 & maio/ago. 2018 & eISSN 2178-8359 \\
\hline
\end{tabular}




\section{RELATO DE EXPERIÊNCIA}

Zabalza (2004) e Masetto (1998) revelam que podem ser atribuídas como competências gerenciais ao docente do ensino superior divulgação científica, produção científica, gestão acadêmica universitária, orientação e supervisão, participação de bancas e comissões julgadoras, avaliação Institucional, extensão, docência e pesquisa. Além destas competências, na era digital, segundo Perez Gomes (2015), o docente enfrenta novos desafios. Novas possibilidades de conhecimentos são produzidas no contexto com TIC, através das redes sociais, internet e plataformas digitais e nestes novos cenários o docente adquire outras habilidades em sua prática pedagógica integrando o uso das TIC. Para Mercado (2015), o desafio consiste na adaptação ao novo modelo de ensino com TIC, propiciar vivências e experiências com tecnologias na prática educativa multiletradas com saberes coletivos que exigem participação, iniciativas, cooperação na solução de problemas, letramento digital, sonoro e informacional; aprender e desenvolver atividades dinâmicas que envolva as TIC na perspectiva da Pedagogia da Autoria com competências para lidar com estudantes multitarefas. Com o desenvolvimento tecnológico, ampliam-se as competências gerenciais do docente do ensino superior. Segundo Mauri e Onrubia (2010), o docente em ambientes virtuais aprende a dominar e valorizar nova cultura da aprendizagem; domina as TIC com formações contínuas e neste processo acontece a interação entre docente-estudante, que passa a conhecer as diversas ferramentas tecnológicas flexibilizando o ensino através de atividade interativa Institucional.

Com a integração das TIC ao processo ensino aprendizagem, o docente aprende a organizar e atribuir significado e sentido às novas informações, como também desenvolver habilidades e capacidade de gestão do aprendizado, do conhecimento e da informação devido ao fato de que as TIC proporcionam, segundo Bernabé (2012), novas oportunidades para educação e formação, facilitando a colaboração, a inovação e a criatividade tanto dos estudantes, como dos docente e IES. No cenário atual do ensino superior, a docência universitária se revela como uma tarefa complexa, devido às várias funções que desempenha. Para Zabalza (2004, p. 111), “[...] ensinar é uma tarefa complexa à medida em que exige conhecimento consistente acerca da disciplina ou das suas atividades". Por isso, o docente, além de conhecer os conteúdos deve ter desenvolvimento na área do conhecimento; desenvolvimento no aspecto afetivo-emocional; desenvolvimento de habilidades e desenvolvimento de atitudes e valores (MASETTO, 1998). O que significa para Cruz Ramos (2010) que a identidade e habilidades do docente do ensino superior aconteça pela prática pedagógica, pela formação profissional, pelo processo evolutivo e singular das experiências dinâmicas e culturais.

A formação da identidade do docente universitário é evolutiva e singular, acontece pela indissociabilidade entre ensino, pesquisa e extensão, de forma individual e institucional. A formação profissional acontece de forma simultânea com a formação acadêmica que fornece competências para uma determinada área, domínio na área pedagógica no exercício de dimensão política. Os saberes teóricos e práticos construtores da identidade docente

\begin{tabular}{l|c|c|c|c|c|c} 
(C) Rev. Educ. Perspec. & Viçosa, $M G$ & v.9 & n.2 & p.453-478 & maio/ago. 2018 & eISSN 2178-8359 \\
\hline
\end{tabular}


acontecem pela formação contínua e permanente, regida pelo art. 66 da Lei de Diretrizes e Bases, Lei $\mathrm{n}^{\circ}$ 9.394/96, que determina prioritariamente formação em mestrado e doutorado. A construção da identidade docente é processual e dinâmica dentro de uma conjuntura para desconstruir visões como "quem sabe, automaticamente, sabe ensinar" ou "só quem sabe investigar, pode realmente ensinar" (CRUZ RAMOS, 2010, p. 33). Segundo Fávero e Tauchen (2013) a gestão profissionalizante do docente se desenvolve pela produção do "pesquisador docente, que desenvolve prática de produção científica e aulas acessórias e docente pesquisador, que tem como foco principal o ensino como pesquisa, desenvolve ações de extensão, mas, não possui produção de pesquisa". A construção da identidade do docente universitário inicialmente atende o desejo do próprio docente, em buscar caminhos para docência voltada para o ensino, para uma docência baseada na aprendizagem (FÁVERO; TAUCHEN, 2013). A ampliação das atividades do docente do ensino superior ocorrida nas últimas décadas, vem redesenhando o perfil e a identidade dos mesmos. A prática pedagógica, por sua vez, não fica limitada em mostrar o que está feito ou acumulado historicamente, pois necessita de ações que englobam conhecimentos tanto cognitivos, quanto não cognitivos, com propostas de conteúdos e tarefas que envolvam atividade construtiva individual e coletiva. A utilização das TIC no processo de aprendizagem interligam as novas tecnologias às metodologias de trabalho que podem melhorar as habilidades dos docentes em criar novas maneiras para enfrentar as tarefas que, por sua vez mudam a natureza da atividade universitária.

\section{METODOLOGIA DE ENSINO E APRENDIZAGEM NO ENSINO SUPERIOR}

No processo de construção do conhecimento, o docente do ensino superior dotado de conhecimentos, habilidades e práticas-reflexivas, através de sua prática pedagógica leva os estudantes desenvolver o senso crítico e reflexivo, acerca das discussões atuais do mundo contemporâneo, que perpassa os conteúdos a serem estudados, dentro e fora da IES. Para Gemignani (2012), o grande desafio das IES na contemporaneidade é a busca por metodologias inovadoras que possibilitem uma práxis pedagógica capaz de ultrapassar os limites do treinamento puramente técnico e tradicional, para efetivamente alcançar a formação do sujeito como um ser ético, histórico, crítico, reflexivo, transformador e humanizado. Para democratizar o processo de ensino aprendizagem em sala de aula com práticas pedagógicas permeadas pela pesquisa, o docente é levado construir proposta construtivista para o ensino superior que consiste em educar para a autonomia, através de metodologias ativas e inovadoras, para a descoberta, utilizando-se da pesquisa, participação dos estudantes, trabalhos em grupo, como meio de aprofundar e ressignificar os conhecimentos. O desenvolvimento do conhecimento para a liberdade é uma atividade que requer do docente método ativo, domínio na temática, recursos metodológicos e didáticos que atendem os objetivos propostos. Para Debald (2003, p. 1)

\begin{tabular}{l|l|l|l|l|l|l} 
(c) Rev. Educ. Perspec. & Viçosa, $M G$ & v.9 & n.2 & p.453-478 & maio/ago. 2018 & eISSN 2178-8359 \\
\hline
\end{tabular}


a prática pedagógica no Ensino Superior deve ser encarada com muita seriedade. Requer posturas e comprometimentos com um processo que eduque para a autonomia do acadêmico, mediado pelo professor. Somente uma educação que tenha como princípio a liberdade, poderá auxiliar na construção de uma sociedade mais humanizada.

O processo da construção do saber não é tarefa fácil de ser desenvolvida, pois, em muitos casos a dificuldade não está em abordar o conteúdo, mas especificamente na metodologia que atenda as expectativas dos discentes. Abreu e Masetto (1990) afirmam que o conhecimento e o domínio das estratégias é uma ferramenta que o professor maneja de acordo com sua criatividade, sua reflexão e sua experiência, para alcançar os objetivos da aprendizagem”.

Este estudo foi realizado na disciplina "Metodologia do Ensino superior com TIC", no curso de Mestrado e Doutorado em Educação, na turma do segundo semestre de 2016, com objetivo de explorar metodologias educacionais com o uso das TIC como ferramentas norteadoras no processo de promoção e inovação da qualidade do ensino superior.

A disciplina "Metodologia do Ensino Superior com TIC (EDU.123)", com carga horária de 60 horas, foi ofertada no segundo semestre aos mestrandos, doutorandos e alunos especiais do PPGE da UFAL, discute as temáticas: o papel do docente na educação superior no contexto da cultura digital: competências digitais e didáticas, mediação pedagógica; o planejamento, docência e avaliação em aulas com TIC, online e sala de aula invertida; estratégias didáticas com TIC; o planejamento da docência presencial, híbrida e online ou com sala de aula invertida que articulem os diversos saberes, com vistas ao desenvolvimento de aulas inovadoras com TIC; desenvolvimento das competências com TIC requeridas no ensino superior; avaliação da aprendizagem no ensino superior e recursos online para as avaliações formativa e somativa.

$\mathrm{Na}$ disciplina foram trabalhados os seguintes objetivos de aprendizagem: refletir sobre o trabalho docente no ensino superior, propiciando a articulação dos conhecimentos específicos das diversas áreas aos saberes didáticos e pedagógicos, numa perspectiva de compreensão crítica do papel do docente/pesquisador na dinâmica interna das IES; explorar metodologias para uso de TIC na educação presencial e online e inserir nos cursos de formação de docentes, materiais didáticos interativos e práticas pedagógicas renovadas, a partir da utilização das TIC; utilizar estratégias didáticas e atividades com TIC, desenvolvendo habilidades para utilização, aprendendo a avaliar, selecionar e integrar os recursos tecnológicos nas atividades curriculares: aprendizagem com simulações, dramatização, jogos online, laboratórios ou experimentos virtuais, aprendizagem com projetos: webquest, web inquiry Project, webgincanas, estudos do meio, uso de redes sociais e ferramentas de comunicação; vivenciar práticas de ensino baseadas nos fundamentos da sala de aula invertida usando seus potenciais e desafios na educação superior.

\begin{tabular}{l|c|c|c|c|c|c} 
(C) Rev. Educ. Perspec. & Viçosa, $M G$ & v.9 & n.2 & p.453-478 & maio/ago. 2018 & eISSN 2178-8359 \\
\hline
\end{tabular}




\title{
RELATO DE EXPERIÊNCIA
}

A disciplina foi ministrada na modalidade híbrida, compreendendo o estudo individual com materiais online e leituras indicadas; atividades de aprendizagem, enfatizando a articulação dos estudos teóricos com a prática docente, debate de vídeos no WhatsApp, além de encontros presenciais. Envolveu aulas com debates a partir da leitura e análise crítica de textos, utilizando TIC.

Utilizamos a aprendizagem experiencial, aprendizado cooperativo, aprendizado de aventura e formação prática (apprenticeship), na qual segundo Bates (2016), a formação prática é uma maneira específica de capacitar estudantes em aprender fazendo, enfatiza a aprendizagem em contextos reais em laboratórios, oficinas, formação prática, aprendizagem cooperativa.

A prática experiencial se baseia numa proposta metodológica de aprendizagem centrada no estudante, que se estabelece na convicção de que os sujeitos aprendem fazendo e interagindo. Para Silva (2012, p. 8), são "fomentadas atividades que privilegiem o trabalho prático em equipe e relacionado à resolução de problemas ou o desenvolvimento de habilidades de ordem superior". Miccoli (2014, p. 19) defende a "a importância das experiências de aprendizagem em contextos formais informais, para uma compreensão ampliada do processo. Necessidade de descrições do processo de aprendizagem com foco na experiência. Segundo Miccoli (2010), a experiência pode ser um construto e unidade de análise daquilo que acontece, podendo ser uma via de acesso para a compreensão da complexidade de eventos em salas de aula. Chegar a este construto remonta a um interesse por compreender o processo de aprendizagem sob o ponto de vista daqueles que o vivenciam.

Experiência, segundo Miccoli (2010, p. 31-32), é

\begin{abstract}
processo de natureza complexa e orgânica que constela em si várias outras vivências relacionadas, formando uma teia de relações dinâmicas entre aqueles que a vivenciam, no meio da qual se dá a experiência. Isso faz da experiência ponto de partida para a reflexão, com implicações para sua compreensão, para transformação de seu sentido original, bem como de quem as vivencia.
\end{abstract}

Kolb (1984) desenvolve a abordagem experiencial à aprendizagem, que, para ser significativa deve envolver um ciclo de quatro fases, iniciado pela experiência, seguido pela observação e reflexão sobre essa experiência, continuando na formação de generalizações a partir da reflexão, e que termina com a avaliação dessas generalizações na aplicação dos novos conceitos frente à realidade.

Para Velandia-Mesa, Serrano-Pastor e Martinez-Segura (2017, p. 11, tradução nossa),

a articulação entre a investigação educativa e a prática profissional requer realizar a sistematização da experiência pedagógica, entendida como um exercício permanente de produção de conhecimento crítico desde a prática (JARA, 2012): este processo implica considerar e interpretar o que acontece e reconstruir o que é 
sucedido, incorrendo na identificação de elementos que intervém na experiência desde uma postura crítica, para compreendê-la desde a própria prática.

Destacaremos as metodologias que envolvem o uso de diversas estratégias didáticas com TIC, utilizadas na disciplina, como debate no WhatsApp, elaboração de mapas conceituais e circulares, seminários temáticos com estratégias didáticas com TIC no ensino superior aprendizagem com simulação/dramatização, aprendizagem com projetos: webquest, web inquirity project, webgincanas, aprendizagem a partir de casos, aprendizagem com laboratórios ou experimentos virtuais, aprendizagem com jogos online, aprendizagem baseada em problemas, elaboração de plano de ensino para disciplina do curso superior utilizando as TIC, entrevista com docente universitário, utilizando uma das ferramentas: Facebook, e-mail, chat do gmail, WhatsApp ou Twitter, elaboração de sequências didáticas empregando TIC, elaboração de plano de aula utilizando aplicativo móvel. Construção de blog coletivo para as atividades da turma, avaliação da disciplina e elaboração de artigo contendo estratégias didáticas com TIC no ensino superior.

A dinâmica da disciplina ofereceu uma aprendizagem prática, no sentido da vivência de estratégias didáticas usando TIC e instigando os mestrandos/doutorandos a explorar as ferramentas, de modo a convergir o uso destas em direção de potencializar o processo de ensino e aprendizagem na área do conhecimento e/ou disciplina que atua ou atuará no ensino superior. Na realização das atividades propostas foi utilizada a perspectiva do ensinar e aprender, valorizando a autonomia do mestrando/doutorando e o princípio da pesquisa como aprendizado, proporcionando um vínculo entre teoria e prática, em uma experiência ao longo do curso, que articule conhecimentos e competências.

Cada mestrando/doutorando elaborou propostas didáticas empregando TIC em aulas presenciais, híbridas e online no ensino superior, a partir das diretrizes publicadas no blog "Metodologia do Ensino Superior com TIC" como apoio às aulas. 


\section{RELATO DE EXPERIÊNCIA}

Metodologia do Ensino Superior com TIC
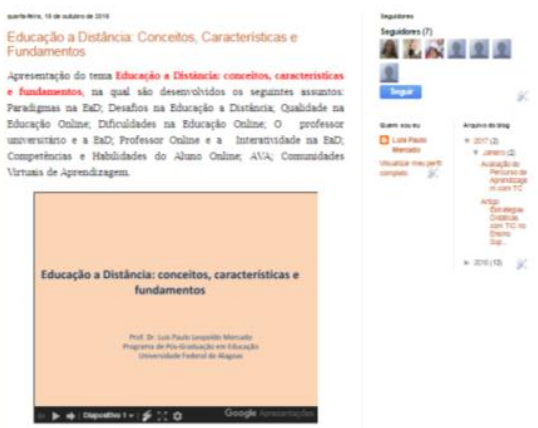

Figura 1. Blog da disciplina Metodologia do Ensino Superior com TIC

Fonte: Blog. Disponível em: <http://mesticufal.blogspot.com.br〉. Acesso em: 20 abr. 2018.

A avaliação da disciplina foi processual, valorizando as atividades realizadas nos momentos presenciais, híbridos e a distância, envolvendo sistematização e organização prévia das atividades, implicando na participação contínua do mestrando/doutorando em todos estes momentos, participação nos seminários, além da elaboração e apresentação de textos com qualidade de publicação acerca do tema escolhido. No decorrer das aulas da disciplina foram realizados vários trabalhos avaliativos (atividades).

Os resultados das atividades individuais, em duplas/trios e em grupo produzidas ao longo das aulas geraram a elaboração de livros digitais, artigos científicos, mapas conceituais e circulares e apresentações no Prezzi postados no blog coletivo da disciplina "Metodologia do Ensino Superior com TIC UFAL 2016".

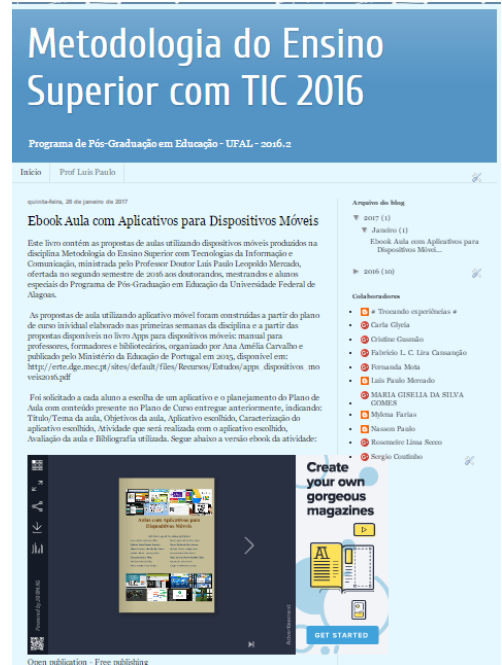

Figura 2. Blog coletivo contendo as produções dos mestrandos/doutorandos da disciplina Fonte: Blog. Disponível em: <http://mesticufal2016.blogspot.com.br/>. Acesso em: 20 abr. 2018. 
Para dar conta das várias atividades propostas ao longo da disciplina, a turma foi distribuída em seis grupos (Quadro 1) para que cada grupo assumisse a responsabilidade pela sistematização final das produções realizadas pelos mestrandos/doutorandos em cada atividade proposta, receber as atividades realizadas pelos outros grupos por e-mail e postar no blog coletivo da turma.

Quadro 1. Grupos do blog coletivo da disciplina

\begin{tabular}{|c|l|}
\hline Grupo & \multicolumn{1}{|c|}{ Organização Blog } \\
\hline Grupo 1 & $\begin{array}{l}\text { Texto e ilustração a partir do vídeo Nação Digital e Bridging Our Future. Participação no } \\
\text { debate no WhatsApp. Contextualização do documentário, relação dos contextos } \\
\text { apresentados com o ensino superior e repercussão nas práticas pedagógicas e nas propostas } \\
\text { docentes. Organização das respostas de todos num único texto ilustrado e publicado no blog. }\end{array}$ \\
\hline Grupo 2 & $\begin{array}{l}\text { Mapas Circulares - Educação Online: conceitos, características e fundamentos. Organização } \\
\text { dos mapas circulares e publicar no blog. }\end{array}$ \\
\hline Grupo 3 & $\begin{array}{l}\text { Mapas Conceituais - O Docente no Ensino Superior: formação, competências e Habilidades. } \\
\text { Organização dos mapas conceituais e publicar no blog. }\end{array}$ \\
\hline Grupo 4 & $\begin{array}{l}\text { Atuação do Docente no Ensino Superior - Entrevistas com convidado. Publicação do roteiro } \\
\text { e das entrevistas no blog. }\end{array}$ \\
\hline Grupo 5 & $\begin{array}{l}\text { Planos de Curso/Disciplina. Organização dos planos de curso/disciplina. Apresentação, } \\
\text { construção de revista digital. }\end{array}$ \\
\hline Grupo 6 & $\begin{array}{l}\text { Seminário: Estratégias Didáticas no Ensino Superior. Organização das apresentações dos } \\
\text { grupos feitas no Prezzi e disponibilizadas no blog. }\end{array}$ \\
\hline
\end{tabular}

Fonte: Organização dos grupos da disciplina

\section{ESTRATÉGIAS DE ENSINO TRABALHADAS NA DISCIPLINA METODOLOGIA DO ENSINO SUPERIOR COM TIC}

A primeira atividade trabalhada na disciplina foi a "Construção do Plano de Disciplina/Curso", a partir das Diretrizes Curriculares Nacionais (DCN) dos cursos de graduação, disponíveis no site do Conselho Nacional de Educação (CNE). Os mestrandos/doutorandos construíram o plano de curso para a disciplina escolhida, contendo ementa, objetivos, conteúdos programáticos, metodologia, avaliação, bibliografia básica e complementar, cronograma de atividades. Os planos de curso foram organizados num único documento transformando em revista eletrônica e disponibilizando no blog coletivo da turma.

\begin{tabular}{l|l|l|l|l|l|l} 
(C) Rev. Educ. Perspec. & Viçosa, $M G$ & v.9 & n.2 & p.453-478 & maio/ago. 2018 & eISSN 2178-8359 \\
\hline
\end{tabular}




\section{RELATO DE EXPERIÊNCIA}

DOI 10.22294/eduper/ppge/ufv.v9i2.978

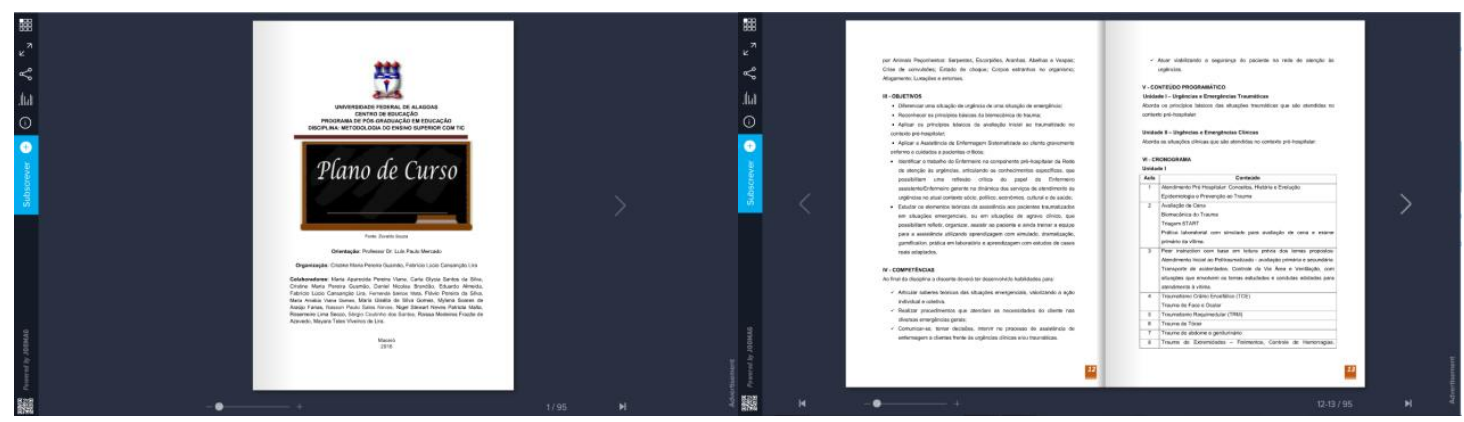

Figura 3. Revista online com os planos de curso dos mestrandos/doutorandos Fonte: Blog. Disponível em: <http://mesticufal2016.blogspot.com.br/>. Acesso em: 20 abr. 2018.

A segunda atividade envolveu a "construção de mapa conceitual", ferramenta gráfica que objetiva organizar e representar o conhecimento. Foi solicitado aos mestrandos/doutorandos que sistematizassem as leituras de referência utilizando o recurso do mapa conceitual, focando o tema "O Docente do Ensino Superior", abordando: identidade, formação, competências e habilidades frente a era digital.

A construção do mapa conceitual ${ }^{1}$ se deu a partir das leituras de Masetto (1998), Cruz Ramos (2010), Mendonça et al. (2013), Fávero (2013), Perez Gomes (2015) e Feldkercher (2016); debates em sala de aula e das questões para discussão: $\mathrm{O}$ que é ser docente universitário?; Como se constrói a identidade do docente do ensino superior?; Por que um excepcional pesquisador não é, necessariamente, um excelente docente?; Que formação é necessária ao docente do ensino superior?; Que saberes são necessários a esse profissional, além do conhecimento disciplinar?; Que tarefas de ensino, pesquisa, extensão, gestão e representação/consultorias institucionais são inerentes ao trabalho do docente do ensino superior?; Quem é o docente pesquisador e pesquisador-docente no atual cenário da educação superior?; Como ocorre o processo formativo do docente universitário?.
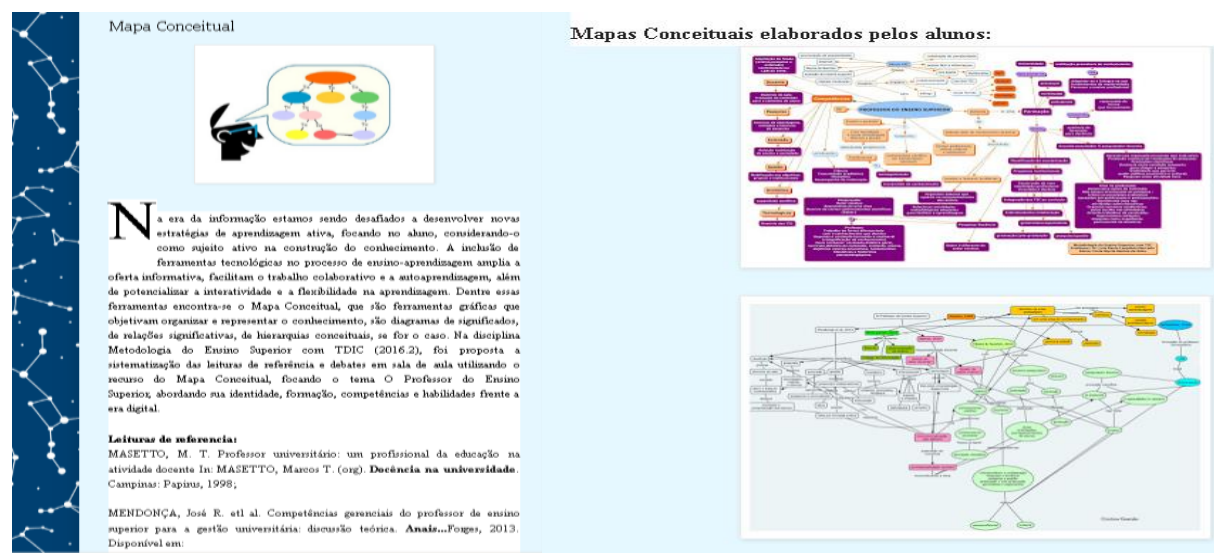

Figura 4. Postagem mapas conceituais no blog coletivo da turma 


\section{RELATO DE \\ EXPERIÊNCIA}

DOI 10.22294/eduper/ppge/ufv.v9i2.978

Fonte: Blog. Disponível em: <http://mesticufal2016.blogspot.com>. Acesso em: 20 abr. 2018.
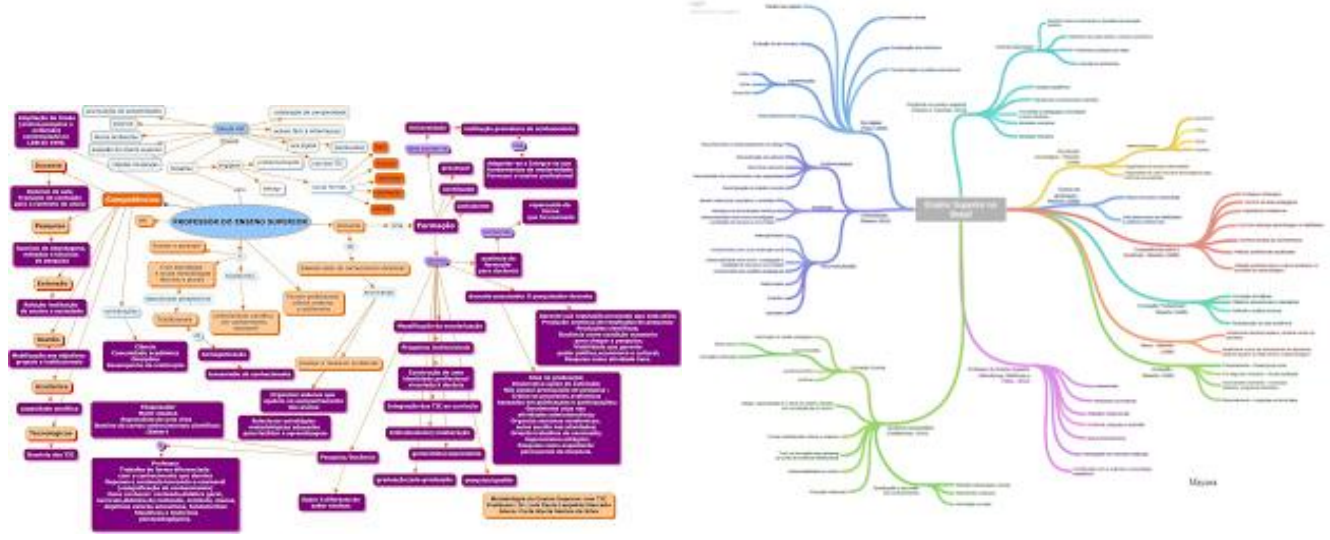

Figura 5. Mapas conceituais elaborados pelos mestrandos/doutorandos

Fonte: Blog. Disponível em: 〈http://mesticufal2016.blogspot.com〉. Acesso em: 20 abr. 2018.

Depois da criação dos mapas conceituais pelos mestrandos/doutorandos, foram apresentados em sala e exposto no blog coletivo da turma. A atividade com mapa conceitual melhora o processo de compreensão dos conteúdos. Conforme Novak e Gowin (1996, p. 32) "[...] ao utilizar-se de mapas conceituais, os mestrandos/doutorandos aumentam a sua compreensão dos conceitos como consequência das suas experiências na sala de aulas e adquirirem atitudes extremamente positivas".

A terceira atividade desenvolvida na disciplina envolveu a "construção coletiva de um texto reflexivo" a partir do debate documentário "Nação Digital e Bridging Our Future” realizado no WhatsApp. O primeiro documentário, Nação digital, analisa a vida na fronteira virtual e as consequências da revolução digital, investiga mudanças sociais ocorridas a partir da internet. Mostra as dificuldades de docentes em desconectar estudantes das redes sociais para conectálos às aulas. Discute o significado de viver no mundo digital do século 21, as implicações de viver em um mundo tecnológico, o impacto da conectividade constante, as relações humanas, profissionais e de lazer neste contexto. O vídeo Bridging Our Future da Intel, mostra situações de sala de aula com tecnologias gamificadas centradas na aprendizagem colaborativa e individualizada.

Com base nas contribuições e discussões dos mestrandos/doutorandos e docente foi construído pelo grupo $1 \mathrm{um}$ texto ilustrado com imagens que resultou no $e$-book postado no blog coletivo da turma.

A atividade aconteceu por meio da comunicação síncrona em tempo real e se caracterizou pela necessidade do docente e mestrandos/doutorandos estarem conectados simultaneamente (ZAINA, 2002). A ferramenta tecnológica utilizada foi o dispositivo móvel celular através do aplicativo WhatsApp. Segundo Merije (2012, p. 51), “a aprendizagem desenvolvida através 
do dispositivo móvel deixa de ser unilateral e potencializa práticas didáticas colaborativas, em que a produção de conteúdos e informações envolve a participação ativa dos próprios estudantes", na qual o processo da aprendizagem acontece pelas trocas, interação e diálogo, potencializando o saber do outro.

Foi solicitada a análise dos dois vídeos e que os mestrandos/doutorandos debatessem no grupo do WhatsApp da turma os seguintes pontos: contextualização do documentário e vídeo; relação dos contextos apresentados com o ensino superior; repercussões na prática pedagógica de cada um a partir de duas situações escolhidas nos vídeos; como docente do ensino superior, que estratégias usar para "desconectar" os estudantes das redes sociais ou tecnologias digitais, para conectá-los às aulas, diante do contexto de estudantes multitarefas em situações de aprendizagem; utilização das tecnologias em proveito das aulas no ensino superior. A partir das contribuições do debate, foi elaborado o e-book "Comunicação Síncrona: uma experiência vivenciada por alunos da pós-graduação em atividade extraclasse utilizando o WhatsApp", resultado da atividade extraclasse utilizando o aplicativo WhatsApp, sobre o tema Educação Superior na Cultura Digital, realizada com a moderação do docente responsável da disciplina.
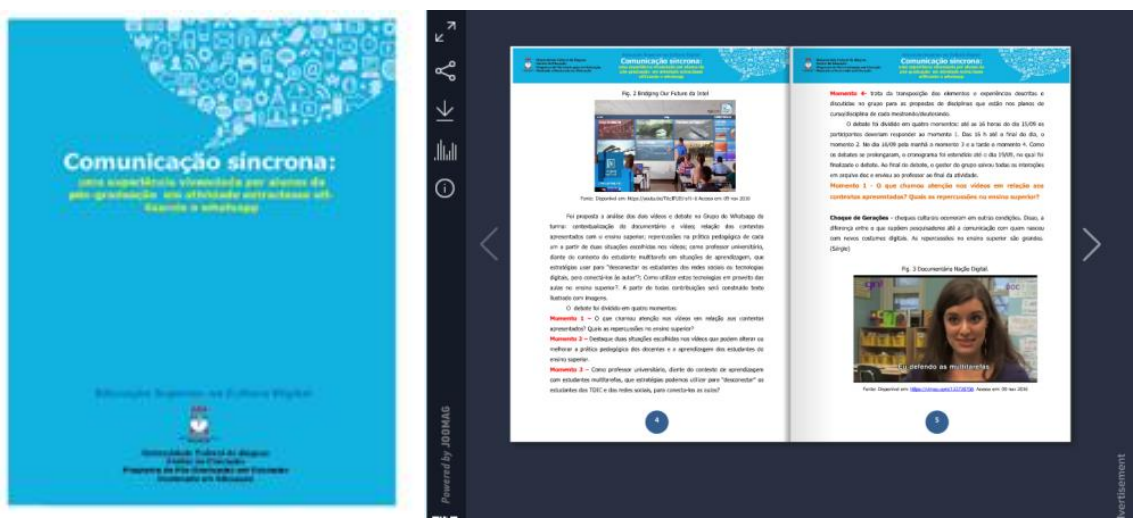

Figura 6. E-book resultante do debate no WhatsApp a partir dos vídeos Nação Digital e Bridginf Our Future

Fonte: Blog. Disponível em: <http://mesticufal2016.blogspot.com>. Acesso em: 20 abr. 2018.

A quarta atividade focou o tema "Atividades do Docente do Ensino Superior", nas quais estes estão inseridos num cenário com inúmeras possibilidades de atuação, fundadas na titulação, experiência (expertise), produção científica reconhecida pelos pares, meritocracia e oportunidades. As principais atividades desenvolvidas pelo docente universitário são: divulgação científica, produção científica, produções técnicas, gestão acadêmica, orientações e supervisões de estudantes, participação de bancas e comissões julgadoras e avaliação institucional. 
Cada mestrando/doutorando convidou um docente do ensino superior e realizou uma entrevista utilizando uma das ferramentas: Facebook, e-mail, chat do gmail, WhatsApp ou twitter. As entrevistas foram realizadas a partir do roteiro: quem será entrevistado; ferramenta de comunicação a ser utilizada; perguntas elaboradas pelos entrevistadores, referentes à atuação no ensino superior (ensino, pesquisa, extensão, gestão, relações institucionais ou representação). O resultado das entrevistas foi enviado ao grupo responsável por esta atividade, para a organização do e-book "Entrevistas com Professores Universitários", contendo todas as entrevistas, disponibilizado no blog com as produções coletivas da disciplina.

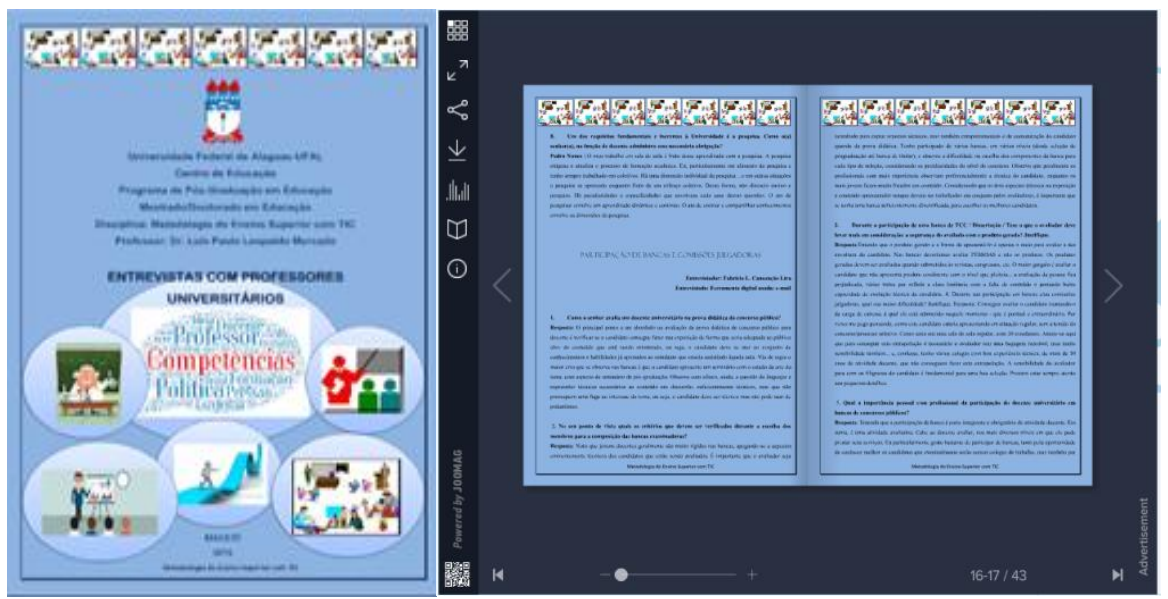

Figura 7. E-book com entrevista dos professores universitários

Fonte: Blog. Disponível em: 〈http://mesticufal2016.blogspot.com〉. Acesso em: 20 abr. 2018.

A quinta atividade envolveu a elaboração do planejamento de aulas com aplicativos de dispositivos móveis. O docente da disciplina enfatizou a importância do plano de aula para a prática docente, visando um melhor desenvolvimento do processo de ensino-aprendizagem e apresentou a estrutura do mesmo: título da aula, objetivo, conhecimentos prévios trabalhados pelo docente com o estudante, desenvolvimento metodológicos, recursos, avaliação e bibliografia. Para a criação de um plano de aula foi solicitada a utilização de aplicativos móveis.

Cada mestrando/doutorando organizou uma aula utilizando aplicativo móvel a partir das propostas disponíveis no livro "Apps para dispositivos móveis: manual para professores, formadores e bibliotecários", organizado por Carvalho (2015) e da exploração de um dos aplicativos para dispositivos móveis trabalhados no livro ${ }^{\mathrm{ii}}$.

A partir da escolha e estudo de um ou mais aplicativos, cada dupla/trio planejou o respectivo plano de aula com conteúdo do Plano de Curso entregue inicialmente, indicando: título/tema da aula; objetivos da aula; aplicativo escolhido; caracterização do aplicativo; atividade

\begin{tabular}{l|c|c|c|c|c|c} 
(C) Rev. Educ. Perspec. & Viçosa, $M G$ & v.9 & n.2 & p.453-478 & maio/ago. 2018 & eISSN 2178-8359 \\
\hline
\end{tabular}


realizada e avaliação da aula com o aplicativo. Foram produzidas as seguintes propostas de aula utilizando aplicativos para educação móvel (Quadro 2).

Quadro 2. Propostas de aulas utilizando aplicativos para dispositivos móveis

\begin{tabular}{|c|c|c|}
\hline Disciplina & Aula & Aplicativo \\
\hline Teoria Geral do Direito Penal 1 & $\begin{array}{l}\text { Princípios Constitucionais Penais e Direitos } \\
\text { Fundamentais }\end{array}$ & GosoapBox \\
\hline Bases da Anatomia Humana. & Bases da Anatomia Humana & Kahoot \\
\hline Didática Geral & Tendências Pedagógicas & $\begin{array}{c}\text { Tondoo, Google Drive e } \\
\text { Powtoon }\end{array}$ \\
\hline Internet e $W e b$ & O que é a Internet/histórico. & Socrative \\
\hline Governança & Governança X Governabilidade & Google Drive \\
\hline Pesquisa Educacional & $\begin{array}{l}\text { Pesquisa Quantitativa e Qualitativa em } \\
\text { Educação }\end{array}$ & Active TextBook \\
\hline $\begin{array}{l}\text { Educação e Novas Tecnologias da } \\
\text { Informação e Comunicação }\end{array}$ & $\begin{array}{l}\text { Utilização do } Q R \text { Code como Recurso } \\
\text { Pedagógico }\end{array}$ & $\begin{array}{c}\text { Kaywa QR Code, Unitag, } \\
\text { Orquiz. }\end{array}$ \\
\hline Currículo & Criação de e-book na disciplina de Currículo & Powtoon e Symbaloo.com \\
\hline Jogos, Recreação e Brincadeiras & Construção de Jogos Didáticos & $\begin{array}{c}\text { Unity } 3 D \\
\text { QR Code Reader }\end{array}$ \\
\hline $\begin{array}{l}\text { Direitos Humanos e Movimentos } \\
\text { Sociais }\end{array}$ & Direitos Fundamentais & Socrative \\
\hline Atendimento Pré-Hospitalar & $\begin{array}{l}\text { Atuação do Enfermeiro em Situação com } \\
\text { Múltiplas Vítimas }\end{array}$ & QR Code \\
\hline Webjornalismo & $\begin{array}{l}\text { Evolução do Webjornalismo: primeira, } \\
\text { segunda e terceira gerações }\end{array}$ & $\begin{array}{l}\text { Hangouts } \\
\text { Text2Mind }\end{array}$ \\
\hline História da Cultura Alagoana. & Cultura Popular: os folguedos de Alagoas. & $\begin{array}{l}\text { Tellagami } \\
\text { Tondoo }\end{array}$ \\
\hline $\begin{array}{l}\text { Laboratório de Webjornalismo e } \\
\text { Jornalismo Multimídia }\end{array}$ & Gerando e refinando pautas & Text2Mind Map \\
\hline
\end{tabular}

Fonte: produções dos mestrandos/doutorandos da disciplina.

Após a elaboração dos planos de aula, os mestrandos/doutorandos enviaram para o grupo responsável pela sistematização das propostas produzir o $e$-book "Aulas com Aplicativos para Dispositivos Móveis", com as propostas de aulas utilizando dispositivos móveis entregues. 


\section{RELATO DE EXPERIÊNCIA}

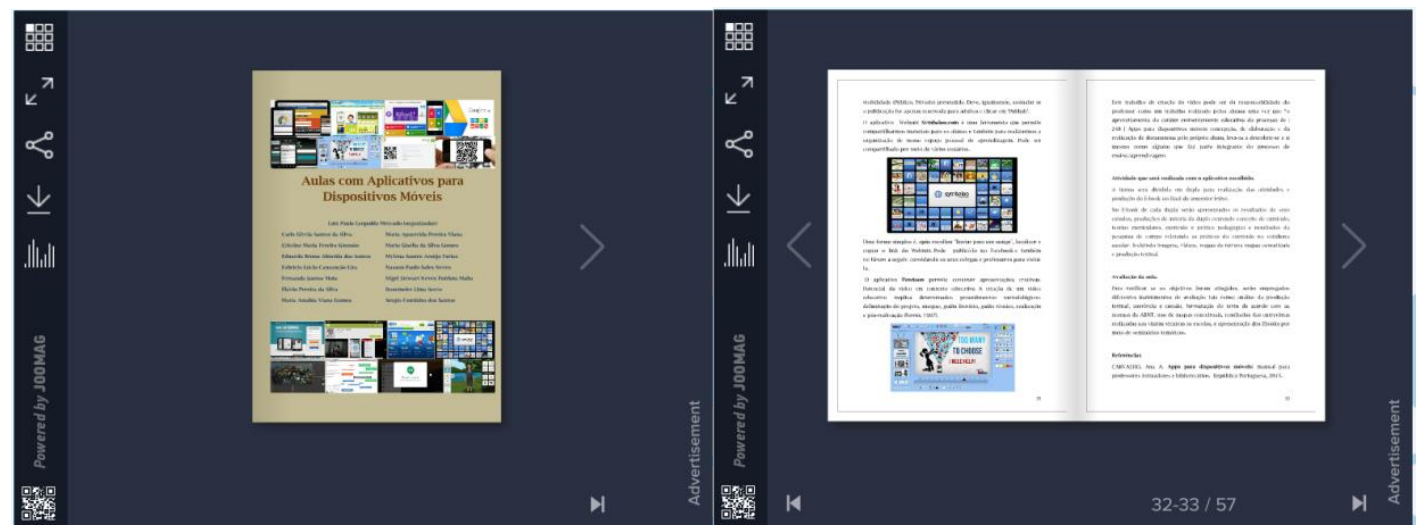

Figura 8. Ebook Aulas com Aplicativos para Dispositivos Móveis

Fonte: Blog. Disponível em: <http://mesticufal2016.blogspot.com>. Acesso em: 20 abr. 2018.

A sexta atividade envolveu atividade híbrida com o tema "Educação a Distância: conceitos, características e fundamentos", na qual foram discutidos os temas: paradigmas na educação a distância (EaD;) desafios na $\mathrm{EaD}$; qualidade na educação online; dificuldades na educação online; o docente universitário e a $\mathrm{EaD}$; docente online e a interatividade na $\mathrm{EaD}$; competências e habilidades do estudante online; Ambiente Virtual de Aprendizagem (AVA); comunidades virtuais de aprendizagem. Foi proposta atividade extraclasse de explorar módulos do curso online no AVA "Moodle Curso Formação de Professores para a Docência Online, ${ }^{\text {,iii }}$.

A sétima atividade desenvolvida na disciplina envolveu a construção de mapa circular focando o tema "Docência Online: conceitos, características e fundamentos", a partir da leitura de no mínimo três dos textos: Silva (2006), Mauri e Onrubia (2010), Monereo e Pozo (2010), Backes e Schlemmer (2013), Sá e Silva (2013), Silva e Cilento (2014), Harasim (2015), Mercado (2015), Araújo e Peixoto (2016), contendo: desafios, cenários, formas de atuação, estratégias necessárias para ensinagem na educação online, competências que o docente/tutor necessita desenvolver para professorar em contextos online.

Os mestrandos/doutorandos elaboraram mapas circulares a partir de leitura de textos indicados pelo docente, disponível no blog da disciplina. Após lerem artigos científicos, os estudantes abordaram os cenários encontrados e a forma de atuação docente, além das estratégias para o ensino na educação online e as competências que o docente/tutor precisa desenvolver. O grupo 2 ficou responsável em receber os mapas circulares dos demais colegas organizar e postar no blog coletivo da turma. 

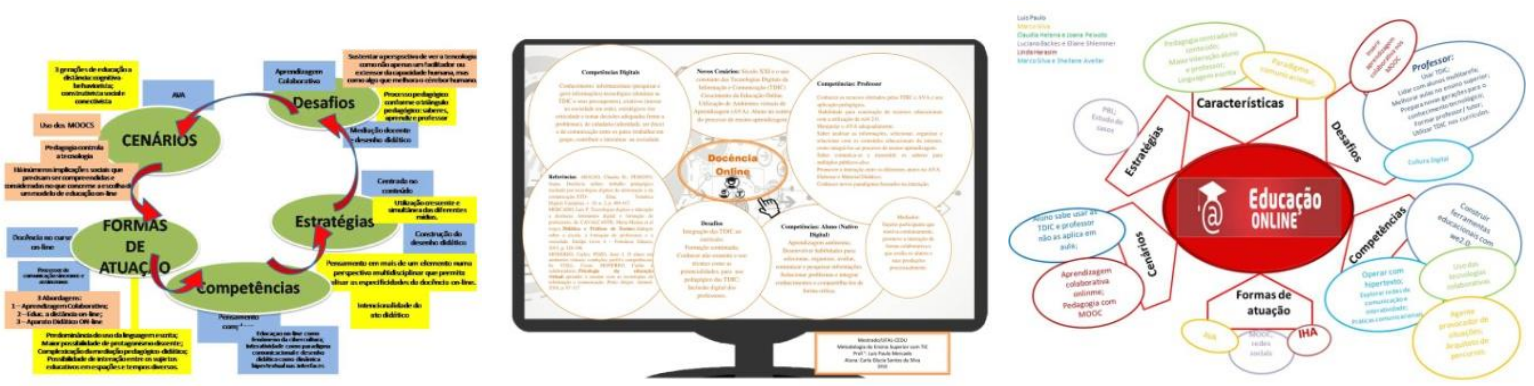

Figura 9. Alguns Mapas circulares produzidos pelos mestrandos/doutorandos Fonte: Blog. Disponível em: <http://mesticufal2016.blogspot.com>. Acesso em: 20 abr. 2018.

A oitava atividade desenvolvida teve como tema "Inovação no Ensino Superior: estratégias didáticas com TIC no ensino superior utilizando metodologias ativas" e teve como objetivo apresentar propostas com diferentes estratégias didáticas no ensino superior; fundamentar teoricamente e elaborar sequência didática envolvendo a estratégia estudada. Os mestrandos/doutorandos foram divididos em seis grupos para a realização da atividade e cada um realizou a leitura do material disponibilizado no blog da disciplina e dos materiais resultantes da pesquisa webgráfica, ampliando os estudos acerca das possibilidades de uso nas aulas do ensino superior, das estratégias didáticas. Foram organizados seis grupos dos seminário sobre estratégias didáticas com TIC no ensino superior (Quadro 3).

Quadro 3. Grupos dos seminários estratégias didáticas com TIC no ensino superior

\begin{tabular}{|c|c|}
\hline Grupo & Seminário \\
\hline Grupo 1 & Aprendizagem com Simulação/Dramatização \\
\hline Grupo 2 & Aprendizagem com Projetos: Webquest, Web Inquiry Project, Webgincanas \\
\hline Grupo 3 & Aprendizagem a partir de Casos \\
\hline Grupo 4 & Aprendizagem Experiencial com Laboratórios ou Experimentos Virtuais \\
\hline Grupo 5 & Aprendizagem com Jogos Online \\
\hline Grupo 6 & Aprendizagem Baseada em Problemas (ABP ou PBL) \\
\hline
\end{tabular}

Fonte: Blog da disciplina

Cada grupo fez a leitura do material disponibilizado no blog ampliando, através da pesquisa webgráfica, os estudos acerca das possibilidades de uso das estratégias didáticas nas aulas do ensino superior. A partir da organização e leitura dos materiais selecionados, cada grupo construiu uma apresentação no Prezzi, abordando os aspectos: características da estratégia didática estudada; fundamentos teóricos da aprendizagem; vantagens e desvantagens em utilizar a estratégia no ensino superior; uso das TIC nas estratégias estudadas em disciplinas do ensino superior; proposta de utilização da estratégia estudada; plano de aula para cada plano de curso dos componentes do grupo; construção de aulas/sequência didática utilizando a estratégia estudada (tema, objetivos, desenvolvimento da aula, avaliação) envolvendo a utilização de recursos das TIC. Depois de apresentados e discutidos em sala de aula pelos grupos, os seminários foram postados no blog da turma pelo grupo 6.

\begin{tabular}{l|l|l|l|l|l|l} 
(C) Rev. Educ. Perspec. & Viçosa, $M G$ & v.9 & n.2 & p.453-478 & maio/ago. 2018 & eISSN 2178-8359 \\
\hline
\end{tabular}




\section{RELATO DE EXPERIÊNCIA}
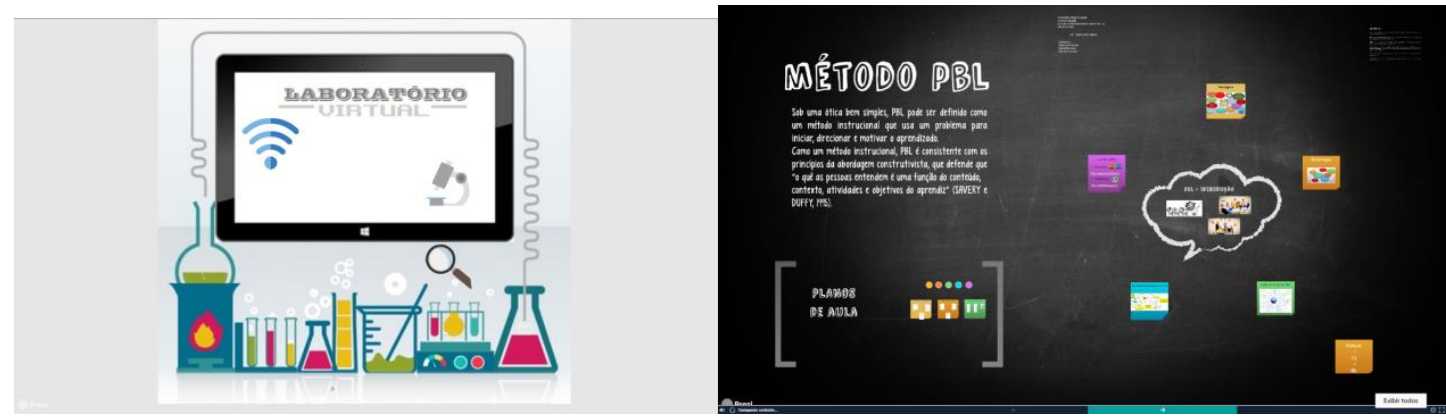

Figura 10. Apresentações dos seminários produzidas no Prezzi

Fonte: Blog. Disponível em: 〈http://mesticufal2016.blogspot.com〉. Acesso em: 20 abr. 2018.

No final da disciplina, foi proposta a escrita de artigo na temática "Estratégias Didáticas com TIC no Ensino Superior" na disciplina escolhida, escrito individualmente (doutorandos) ou em dupla (mestrandos e alunos especiais). O docente disponibilizou no blog da disciplina um roteiro para produção escrita do artigo com base nas normas da ABNT. Os artigos ${ }^{\text {iv }}$ entregues ao final da disciplina retrataram as experiências inovadoras no ensino superior e após as revisões pelo docente foram encaminhados para publicação em periódicos Qualis e congressos internacionais da área.

A estrutura do artigo seguiu o roteiro: fundamentação teórica com a descrição da estratégia didática estudada e TIC escolhidas: conceitos, objetivos, formas usuais de utilização, exemplos de utilização em atividades com os estudantes; análise: limitações, potencialidades, críticas, propostas inovadoras, oportunidades de uso na educação; proposta de aulas utilizando o material estudado na disciplina escolhida.

O uso de diversas estratégias de ensino na prática em sala de aula, tornando-se a aprendizagem mais dinâmica, prazerosa, criativa possibilitou uma construção significativa do conhecimento. Segundo Mercado (2016), para que estas estratégias tenham eficiência, precisam ser planejadas antecipadamente, integrar temáticas relevantes para o estudante, recursos que auxiliem no estudo, formular objetivos para auxiliar na exploração, estudo e produção de conhecimento sobre o assunto estudado. Na metodologia escolhida é necessário constar atividades que envolvam resolução de problemas e conduzam ao entendimento proposto e a avaliação processual com foco no que foi sugerido, pode ser feita individualmente e/ou em grupo. 


\section{AVALIAÇÃO DA DISCIPLINA}

O encerramento da disciplina se deu com a "Avaliação do Percurso da Aprendizagem com TIC" postada nos comentários do blog da disciplina, na qual cada mestrando/doutorando avaliou seu percurso de aprendizagem na disciplina, enfocando a importância das TIC na prática docente, as possibilidades vislumbradas do uso das TIC nas aulas, aprendizagem nas aulas de Metodologia do Ensino utilizando TIC, o que precisa melhorar na aprendizagem utilizando TIC, a metodologia utilizada pelo docente da disciplina e sugestões para melhoria da disciplina em futuras ofertas.

Quanto a importância das TIC na prática docente, os mestrandos/doutorandos enfatizaram a necessidade da utilização das TIC na prática docente:

É de fundamental importância a inserção das TIC no contexto educacional, para facilitar o processo didático pedagógico, buscando uma melhoria significativa no desempenho do aluno, as gerações têm contato cada vez mais cedo e mais intenso tanto com os aparelhos como também com as redes, então é imprescindível que se esteja familiarizado e se traga também para o meio educativo e não somente distrativo (C).

$\mathrm{Na}$ área de educação vislumbramos possibilidades de mudanças através do aproveitamento do potencial pedagógico que as TIC possuem. Tendo isso em vista, a prática docente deve buscar relacionar essas possibilidades no processo de ensinoaprendizagem para torná-lo cada vez mais dinâmico e prazeroso, além de significativo para os sujeitos que já se utilizam delas em outras instâncias sociais (CA).

A disciplina nos oportunizou aprender, socializar e trocar experiências, conhecimentos com um professor que nos inspira a ser professor(a), que não tem medo de aprender, está aberto as aprendizagens com os alunos e que nos provoca a conhecer, a utilizar diversas e distintas tecnologias na sala de aula (A).

Questionados acerca da aprendizagem nas aulas de Metodologia do Ensino utilizando TIC, os mestrandos/doutorandos indicaram:

Ampliei meus conhecimentos e minha visão sobre as possibilidades existentes, com destaque para os aplicativos que podem ser utilizados em diferentes plataformas celular, tablet e computadores. Conheci estudos científicos relevantes sobre o uso das TIC, provando que estas tecnologias podem ser utilizadas com embasamento teórico e não apenas de forma aleatória (M).

A forma de estudar de forma intensa num curto período de tempo e com variadas estratégias didáticas utilizando TIC trabalhadas na disciplina é importante para refletir sobre a nossa própria prática profissional em sala de aula e como muitas vezes trabalhamos no automático, repetindo estratégias já dominadas, as vezes por falta de tempo ou de disposição (NA).

O uso de ferramentas desconhecidas até então, foi o grande combustível para a continuação na disciplina, além do esclarecimento do arcabouço legal e as ferramentas online para o desenvolvimento do conhecimento, acredito que foram as

\begin{tabular}{l|l|l|l|l|l|l} 
() Rev. Educ. Perspec. & Viçosa, $M G$ & v.9 & n.2 & p.453-478 & maio/ago. 2018 & eISSN 2178-8359 \\
\hline
\end{tabular}


maiores contribuições, pois tinha muito receio de usar algumas coisas disponíveis, principalmente por desconhecê-las, o que fora desmistificado $(\mathrm{C})$.

As aulas foram um laboratório e levo como experiência para minhas práticas educativa $(\mathrm{MG})$.

Há tempo venho trabalhando com produção de material didático para educação a distância e muitas possibilidades me foram dadas. Vencemos muitos desafios e verifico que sempre nos deparamos com novos sistemas ou tecnologias que podem ser aplicados na educação. As aulas auxiliaram muito no conhecimento destas tecnologias e das novas formas de ensinar e aprender (FL).

As práticas inovadoras que aprendi na disciplina, algumas delas a medida em que eu ia aprendendo, trabalhava na sala de aula: debates no WhatsApp com a mediação docente, a partir de um trabalho planejado e articulado pedagogicamente, utilização de mapa conceitual, mapa circular, estratégias ricas e significativas que pouquíssimos alunos conhecem e realizam no ensino superior. Os mestrandos/doutorandos realizaram entrevistas com professores de IES e utilizaram aplicativos para dispositivos móveis, todas as atividades desenvolvidas foram postadas no blog, coordenada por alunos (A).

Os mestrando/doutorandos enfatizaram o que precisam melhorar na aprendizagem utilizando TIC:

Ficamos empolgados com o conteúdo apresentado pelo professor, de modo que os aplicativos e ferramentas digitais tomam toda a nossa atenção, pois procuramos desbravá-los para utilizarmos imediatamente em nossas aulas (NI).

Conhecer com mais detalhes algumas ferramentas tecnológicas que podem ser usadas como recurso metodológico em sala de aula $(\mathrm{F})$.

Melhorar a organização do plano de desenvolvimento de curso e de aula, principalmente na questão avaliação (C).

Aprendemos muito e o fruto desse aprendizado é a socialização do saber, as práticas diferentes, que geram conhecimento, prazer no aprendizado, aguça a vontade do estudante continuar investindo responsavelmente nos seus estudos, além de ter o professor como grande referência para sua vida pessoal e profissional (A).

\section{CONSIDERAÇÕES FINAIS}

As estratégias didáticas apresentadas no relato, fruto da experiência na disciplina "Metodologia do Ensino Superior com TIC", permitem a oportunidade para os mestrandos/doutorandos em ampliar os conhecimentos pedagógicos e metodológicos, que possibilitarão um processo de ensino-aprendizagem mais prazeroso e dinâmico.

$\mathrm{O}$ uso das TIC no ensino superior precisa ser feito com intencionalidade pedagógica previamente planejada, visando alcançar os objetivos propostos. Com as mudanças constantes nas tecnologias, a pesquisa, o estudo, a formação e o ensino acompanharão o fazer e o inovar da prática pedagógica do docente. As atividades didáticas desenvolvidas na disciplina contribuíram para a prática pedagógica do docente no ensino superior, dinamizar as aulas,

\begin{tabular}{l|c|c|c|c|c|c} 
(C) Rev. Educ. Perspec. & Viçosa, $M G$ & v.9 & n.2 & p.453-478 & maio/ago. 2018 & eISSN 2178-8359 \\
\hline
\end{tabular}


possibilitando interação entre os mestrandos/doutorandos e docente.

Através das postagens das atividades no blog coletivo da turma constatamos que ensinar com a utilização das TIC estimula a competência de autonomia do estudante para o desenvolvimento de seu potencial criativo, intelectivo, reflexivo e interativo. Os mestrandos/doutorandos, na utilização de estratégias didáticas e atividades com TIC, desenvolveram habilidades para utilização destas na prática pedagógica, aprendendo a avaliar, selecionar e integrar os recursos tecnológicos nas atividades curriculares. Com o desenvolvimento das atividades, demonstraram conhecimento entre teoria e prática, com experiências práticas ao longo da disciplina, articulando conhecimentos e competências.

Os desafios impostos ao docente do ensino superior na atualidade são muitos. A articulação da pesquisa, docência, gestão, administração, extensão e outras atividades de sua competência não é tarefa fácil, pois no contexto das competências e habilidades frente a era digital (MASSETO, 1998; PEREZ GOMES, 2005) os docentes do ensino superior adquirem competências e habilidades em formação continuada para usar as TIC na prática pedagógica de aprendizagem colaborativa/multiletrada/interativa (MERCADO, 2015).

A abordagem colaborativa e prática utilizada de forma híbrida na disciplina, com o uso de redes sociais e ferramentas colaborativas e encontros presenciais, motivou os participantes sobre o uso de recursos de TIC. A metodologia usada foi fundamental para os estudantes compreenderem melhor a importância das TIC como recurso metodológico, como também ter acesso de forma prática ao uso das mesmas, visto que o docente relacionou teoria à prática. $\mathrm{O}$ despertar para novas possibilidades de ensinagem desenvolvidas na disciplina foi fundamental, assim como as trocas de experiências de colegas que já atuam na área e os que de alguma forma apresentaram meios de atuar, como também a postura do docente e suas estratégias didáticas que ofereceu um tom colaborativo e autônomo ao mesmo tempo, dinâmico e eficiente para a aprendizagem.

As estratégias didáticas utilizadas na disciplina foram plenamente desenvolvidas, os mestrandos/doutorandos demonstraram que alcançaram os objetivos propostos, pesquisaram, analisaram, produziram, interagiram no blog coletivo, passaram de passivos para ativos no processo de construção do saber, do conhecimento ativo/reflexivo.

\section{REFERÊNCIAS}

ABREU, Maria Célia; MASETTO, Marcos Tarcíso. O professor universitário em aula. São Paulo: MG Editores, 1990.

\begin{tabular}{l|l|l|l|l|l|l} 
(C) Rev. Educ. Perspec. & Viçosa, $M G$ & v.9 & n.2 & p.453-478 & maio/ago. 2018 & eISSN 2178-8359 \\
\hline
\end{tabular}


ARAUJO, Claudia Helena; PEIXOTO, Joana. Docência online: trabalho pedagógico mediado por tecnologias digitais da informação e da comunicação. ETD- Educ. Temática Digital, Campinas, v. 18, n. 2, p. 404-417. Disponível em:

http://periodicos.sbu.unicamp.br/ojs/index.php/etd/article/view/8639484/13322. Acesso em: 10 mar. 2017.

BACKES, Luciana; SCHLEMMER, Eliane. Práticas pedagógicas na perspectiva do hibridismo tecnológico digital. Rev. Diálogo Educ, Curitiba, v. 13, n. 38, p. 243-266, jan./abr. 2013. Disponível em: http://www2.pucpr.br/reol/pb/index.php/dialogo?dd1=7644\& dd99=view\&dd98=pb. Acesso em: 10 mar. 2017.

BATES, Anthony. Educar na era digital: design, ensino e aprendizagem. São Paulo: Artesanato Educacional, 2016.

BERNABÉ, Iolanda. Os professores como aprendizes com as TIC. In: BARBA, Carme; CAPELA, Sebastiá (Org.). Computadores em sala de aula: métodos e usos. Porto Alegre: Penso, 2012. P. 77-83.

CARVALHO, Ana Amélia. Apps para dispositivos móveis: manual para professores, formadores e bibliotecários. Lisboa: Ministério da Educação de Portugal, 2015. Disponível em: http://erte.dge.mec.pt/sites/default/files/Recursos/Estudos/apps_dispositivos moveis2016.pdf. Acesso em: 14 out. 2016.

DEBALD, Blasius Silvano. A docência no ensino superior numa perspectiva construtivista. Seminário Nacional Estado e Políticas Públicas no Brasil. Anais... Cascavel: PR, 2013.

FAVERO, Altair Alberto; TAUCHEN, Gionara. Docência da educação superior: tensões e possibilidades de gestão da profissionalização. Acta scientiarum, Maringá, v. 35, n. 2, p. 235-242, jul./dez. 2013. Disponível em: http://periodicos.uem.br/ojs/index.php/ActaSci Educ/article/view/20074. Acesso em: 10 mar. 2017.

FELDKERCHER, Nadiane. Docência universitária: o professor universitário e sua formação. Práxis Educacional, Vitória da Conquista, v. 12. n. 22, p. 221-245, maio/ago. 2016. Disponível em: http://periodicos.uesb.br/index.php/praxis/article/viewFile/5819/5619. Acesso em: 14 out. 2016.

FERREIRA, Daniela Elisa. Experiências de aprendizagem no contexto on-line: narrativas dos estudantes do Projeto Ingrede. 2012. 139 f. Dissertação (Mestrado). Programa de PósGraduação em Estudos Linguísticos. Faculdade de Letras. Belo Horizonte, MG, 2012.

GEMIGNANI, Elizabeth Yu Me Yut. Formação de professores e metodologias ativas de ensino aprendizagem: ensinar para a compreensão. Revista Fronteiras da Educação [online], Recife, v. 1, n. 2, p. 1-27, 2012. Disponível em: http://www.fronteirasdaeducacao.org/index.php/fronteiras/article/view/14. Acesso: 3 mar. 2017.

\begin{tabular}{|c|c|c|c|c|c|}
\hline (C) Rev. Educ. Perspec. & Viçosa, $M G$ & v. 9 & n. 2 & p. $453-478$ & eISSN 2178-8359 \\
\hline
\end{tabular}


HARASIM, Linda. Educação online e as implicações da inteligência artificial. Revista da Faaeba - Educação e Contemporaneidade. Salvador, v. 24, n. 44, p. 25-39, jul./dez. 2015. Disponível em: http://www.revistas.uneb.br/index.php/faeeba/article/view/1818/1232. Acesso em: 14 out. 2016.

JARA, Oscar. Sistematización de experiências, investigación y evaluación: aproximaciones desde três ângulos. The International Journal for Global and Development Education Research, ano 1, p. 56-70, 2012.

KOLB, David. Experiential learning: experience as the source of learning and development. Englewood Cliffs, NJ: Prentice Hall, 1984.

MASETTO, Marcos Tarciso. Professor universitário: um profissional da educação na atividade docente. In: MASETTO, Marcos Tarciso (Org.). Docência na universidade. Campinas: Papirus, 1998. p. 21-28.

MAURI, Teresa; ONRUBIA, Javier. O professor em ambientes virtuais: perfil, condições e competências. In: COLL, Cesar; MONEREO, Carles e colaboradores. Psicologia da educação virtual: aprender e ensinar com as tecnologias da informação e comunicação. Porto Alegre: Artmed, 2010. P. 118-135.

MENDONÇA, José Ricardo et al. Competências gerenciais do professor de ensino superior para a gestão universitária: discussão teórica. Anais... Forges, 2013. Disponível em: http://docplayer.com.br/14432775-Competencias-gerenciais-do-professor-de-ensino-superiorpara-a-gestao-universitaria-discussao-teorica.html. Acesso em: 14 out. 2016.

MERCADO, Luis Paulo. Metodologias de ensino com tecnologias da informação e comunicação no ensino jurídico. Avaliação. Campinas, v. 21, p. 263-299, 2016.

MERCADO, Luis Paulo. Tecnologias digitais e educação a distância: letramento digital e formação de professores. In: CAVALCANTE, Maria Marina et al. (Org.). Didática e Práticas de Ensino: diálogos sobre a escola, a formação de professores e a sociedade. Endipe Livro 4. Fortaleza: Eduece, 2015. P. 328-346. Disponível em: https://goo.gl/VA568K. Acesso em 14 out 2016.

MERIJE, Wagner. Movimento: educação e comunicação mobile. São Paulo: Petrópolis, 2012.

MICCOLI, Laura. Ensino e aprendizagem de inglês: experiências, desafios e possibilidades. Campinas: Pontes, 2010.

MICCOLI, Laura. A evolução da pesquisa experiencial: uma trajetória colaborativa. In: MICCOI, Laura (Org.). Pesquisa experiencial em contextos de aprendizagem: uma abordagem em evolução. Campinas: Pontes, 2014. p. 17-75.

MONEREO, Carles; POZO, Juan Ignácio. O aluno em ambientes virtuais: condições, perfil e

\begin{tabular}{l|c|c|c|c|c|c} 
(C) Rev. Educ. Perspec. & Viçosa, $M G$ & v.9 & n.2 & p.453-478 & maio/ago. 2018 & eISSN 2178-8359 \\
\hline
\end{tabular}


competências. In: COLL, Cesar; MONEREO, Carles e colaboradores. Psicologia da educação virtual: aprender e ensinar com as tecnologias da informação e comunicação. Porto Alegre: Artmed, 2010. p. 97-117.

PEREZ GOMES, Ángel. Educação na era digital: a escola educativa. Porto Alegre: Artmed, 2015.

POZO, Juan Ignacio; MONEREO, Carles; CASTELLÓ, Montserrat. O uso estratégico do conhecimento. In: COLL, César; MARCHESI, Álvaro; PALACIOS, Jesús; (Org.).

Desenvolvimento psicológico e educação: psicologia da educação. Porto Alegre: Artes Médicas Sul, 1996. P. 145-160.

CRUZ RAMOS, Katia Maria. Reconfigurar a profissionalidade docente universitária: um olhar sobre ações de atualização pedagógico-didática. Porto: Universidade do Porto, 2010.

SÁ, Helena; SILVA, Marco. Mediação docente e desenho didático: uma articulação complexa na educação online. Rev. Diálogos Educ., Curitiba, v. 13, n. 38, p. 139-159, jan./dez. 2013. Disponível em: http://www2.pucpr.br/reol/pb/index.php/dialogo?

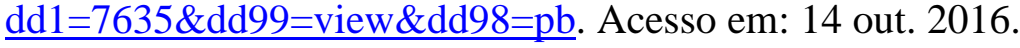

SERRA, Antonio Roberto; SILVA, João Augusto (Org.). Por uma educação sem distâncias: recortes da realidade brasileira. São Luís: Eduema, 2008.

SILVA, Juan. Un modelo pedagógico virtual centrado en las e-actividades. RED - Revista de Educacion a Distância, n. 53, mar. 2017. Disponível em: http://www.um.es/ead/ red/53/silva.pdf. Acesso em: 10 mar. 2017.

SILVA, Marco; SANTOS, Edméa. Avaliação da aprendizagem em educação online. São Paulo: Loyola, 2006.

SILVA, Marco. Criar e professorar um curso online: relato de experiência. In: SILVA, Marco (Org.). Educação online: teorias, práticas, legislação, formação corporativa. 2.ed. São Paulo: Loyola, 2006. p. 53-75.

SILVA, Marco; CILENTO, Sheilane Maria de Avellar. Formação de professores para docência online: considerações sobre um estudo de caso. Revista da Faaeba - Educação e Contemporaneidade. Salvador, v. 23, n. 42, p. 207-218, jul./dez. 2014. Disponível em: http://www.revistas.uneb.br/index.php/faeeba/article/view/1042/720. Acesso em: 14 out. 2016.

VELANDIA-MESA, Cristian; SERRANO-PASTOR, Francisca José; MARTÍNEZSEGURA, Maria José. La investigación formativa em ambientes ubícuos y virtuales en educación superior. Comunicar, n. 51, v. XXV, p. 9-18, 2017.

ZABALZA, Miguel. O ensino universitário: seu cenário e seus protagonistas. Porto Alegre: Artmed, 2004.

\begin{tabular}{l|c|c|c|c|c|c} 
(C) Rev. Educ. Perspec. & Viçosa, $M G$ & v.9 & n.2 & p.453-478 & maio/ago. 2018 & eISSN 2178-8359 \\
\hline
\end{tabular}




\title{
ZAINA, Luciana Aparecida. Acompanhamento do aprendizado do aluno em cursos à distância através da web: metodologias e ferramenta. 2002. 169 f. Dissertação (Mestrado em Engenharia). Escola Politécnica, Universidade de São Paulo, São Paulo, 2002.
}

\section{NOTAS}

\begin{abstract}
${ }^{\mathrm{i}}$ Para a elaboração dos mapas conceituais foram sugeridos ferramentas: Bubbl.us (https://bubbl.us), Cmap Tools (http://cmap.ihmc.us/), Coggle (https://coggle.it/), Comapping (www.copapping.com), Creatily (http://creately.com), Compendium (http://conpendium,open.ac.uk/software.htm), Dropmind (http://dropmind.com), Edraw Mind Map (https://www.edrawsoft.com/freemind.php), $\quad E d x$ (www.edxonline.org), FreeMind (http://freemind.sourceforge.net/wiki/index.php/Min_page), Gliffy (www.gliffy.com), ImindMap (http://www.thinkbuzan.com/es0), Mind42 (http://mind42.com), Mindmanager (http://mindjet.com/products/mindmanager), Mindmeister (http://www.mindmeister.com), Mindmup (http://www.mindmup.com), Mindnode (https://mindnode.com/), Mindomo (http://www.mindomo.com), Nestor (www.gate.cnrs.fr/ zeilliger/nestor.htm), Popplet (http://popplet.com/), Scribblar (http://sribblar.com/), Stormbioard (www.stormboard.com), Tex2midmap (www.text2mindmap.com), Wisemapping (www.wisemapping.com), XMind (https://www.xmind.net/).

ii A exploração solicitada foi de um dos seguintes aplicativos para dispositivos móveis: Active Text Book adiciona interatividade a um PDF e cria quizzes; Aurasma Studio - realidade aumentada; C:Geo - aplicação para geocaching; Calaméo - e-books interativos; Cogi - captura de áudio e partilhar anotações; Edmodo plataforma educativa; Educreations e Show me - transforma o tablet num quadro virtual; Google Drive ferramentas para a sala de aula; GosoapBox - quizzes, sondagens e debates; Habitica - gamificação de aulas; Imagechef - trabalha texto e imagem com criatividade; Kahoot - quizzes, debates e sondagens; LensooCreate transforma o tablet num quadro virtual; Neapod - solução integrada para avaliação, apresentação e colaboração para aulas interativas; Powtoon - apresentações criativas; QRCode - realidade aumentada; Skype, Google Hangouts e Viber - comunicação online; StudyBlue - cartões de estudos digitais; Tagxedo - criação de nuvens de palavras; TeamUp - forma e acompanha equipes; Tellagami -criação e partilha de vídeos, contar histórias; Text2Mindmap - criação de mapas mentais; ToonDoo - criação de banda desenhada; Unity3D - game engine para o desenvolvimento de objetos didáticos gamificados.

iii Disponível em: 〈http://saladeaulainterativa.pro.br/moodle/course/view.php?id=11 > no curso Sala de Aula Interativa. Acesso em: 20 abr. 2018.

iv Foram produzidos os seguintes artigos: Produção de Materiais Didáticos com TIC e Possibilidades de Aprendizagem com Simulação de Dados; TIC na Educação em Direitos Humanos; Monitoramento Online de Governança nas Universidades Federais: proposta de um instrumento; Usos das TIC no PBL na Aprendizagem de Estudantes do Ensino Superior; Estratégias de Ensino: experiência na disciplina Metodologia do Ensino Superior com TIC; A Utilização do Laboratório Virtual como Oportunidade de Aprendizagem no Ensino Superior. O artigo foi enviado por e-mail ao docente da disciplina, revisado por este e refeito pelos autores quando em condições de publicação.
\end{abstract}

\section{SOBRE OS AUTORES}

${ }^{1}$ Luis Paulo Leopoldo Mercado - Doutor em Educação pela Pontifícia Universidade Católica de São Paulo. Professor titular da Universidade Federal de Alagoas. E-mail: luispaulomercado@gmail.com ORCID: http://orcid.org/0000-0001-8491-6152

${ }^{2}$ Maria Gisélia da Silva Gomes - Mestre em Educação pela Universidade Federal de Alagoas. E-mail: zeliasg2016@gmail.com - ORCID: http://orcid.org/0000-0002-7292-8276

\begin{tabular}{l|l|l|l|l|l|l} 
(C) Rev. Educ. Perspec. & Viçosa, $M G$ & v.9 & n.2 & p.453-478 & maio/ago. 2018 & eISSN 2178-8359 \\
\hline
\end{tabular}


${ }^{3}$ Carla Glycia Santos da Silva - Mestranda em Educação pela Universidade Federal de Alagoas. Email: carlaglyufal@gmail.com - ORCID: http://orcid.org/0000-0001-6247-0161 